\title{
Vacuum laser powder bed fusion-track consolidation, powder denudation, and future potential
}

\author{
L. Kaserer ${ }^{1} \cdot$ S. Bergmueller ${ }^{1} \cdot$ J. Braun $^{1} \cdot$ G. Leichtfried ${ }^{1}$ \\ Received: 2 March 2020 / Accepted: 9 September 2020 / Published online: 21 September 2020 \\ (C) The Author(s) 2020
}

\begin{abstract}
Defects in parts processed by laser powder bed fusion (LPBF) are often triggered by laser/plasma plume interference and spattering. The implementation of a LPBF process in vacuum has been suggested to possibly reduce these effects. Within this study, the effects of process pressure variations between 1 mbar and atmospheric pressure on the generation of single tracks and on the surrounding layer of loose powder particles were studied for CP titanium grade 2 and the Maraging steel 1.2709. Below 10 mbar no single tracks could be generated and the powder layer adjacent to the track was effectively denuded. It was found that the essential mechanism for incorporating powder into the melt pool begins to work at process pressures above $10 \mathrm{mbar}$ and its effectiveness increases with increasing pressure. The amount of powder incorporated into the melt pool depends on the material and the scanning conditions. With identical scanning conditions, this amount of powder is significantly larger for titanium than for steel. For process pressures above $200 \mathrm{mbar}$, no significant change in the amount of spattering could be found. In this pressure range improved process stability could be possible due to a reduced laser/plasma interaction and an increased laser penetration depth.
\end{abstract}

Keywords Additive manufacturing $\cdot$ Powder bed fusion $\cdot$ Vacuum $\cdot$ Powder denudation $\cdot$ Single track $\cdot$ Spatter

\section{State of the art}

Laser powder bed fusion (LPBF) is a production method in the field of metal additive manufacturing, which allows to fabricate parts in unique shapes with outstanding mechanical properties $[1,2]$. It has the potential to be a disruptive technology in industries, where end-user customization is highly desirable, where production volume is small, and where end products in highly complex, functionalized geometries are demanded [3]. However, to exploit the full potential of LPBF, the process and its influence on the produced structures need to be well understood. One of these influencing factors is the process pressure. Lowering the process pressure is widely accepted to be beneficial for laser welding [4], a process closely

L. Kaserer

lukas.kaserer@uibk.ac.at

1 Faculty of Engineering Science, Department of Mechatronics, Materials Science, University of Innsbruck, Technikerstrasse 13, 6020 Innsbruck, Austria related to $\mathrm{LPBF}$, but has rarely been investigated for LPBF except for a few studies [5-14].

In one of these studies, Matthews et al. [8] found for Ti64 that the key mechanism for the consolidation of powder particles to a melt track is governed by the process pressure. At atmospheric pressure, metal vapor, caused by superficial overheating in the laser/metal interaction zone, expands jet-like towards the laser beam. As a consequence, a gas flow towards the melt pool is induced. It is strong enough to entrain powder particles within a distance of several hundred $\mu \mathrm{m}$ adjacent to the melt pool $[8,12,14]$. A certain proportion of the particles is absorbed in the melt pool, while the other part becomes hot or cold powder spatter $[9,14,15]$. When the pressure is lowered and the gas flow regime is altered from continuum flow towards a molecular flow, two changes occur simultaneously. First, the expanding metal vapor is less focused, and second, no gas flow can be induced in the surrounding atmosphere, which is capable of entraining particles $[8,12,14]$. The metal vapor, which is expanding in all directions, transports adjacent powder particles away from the melt pool, so that they cannot contribute to the formation of the melt pool. Consequently, studies 
investigating LPBF with process pressure in the molecular flow regime [5-7, 9-11, 14] found increased powder spattering $[8,14,16]$, but no clear evidence for any LPBF process improvements. A process pressure in the continuum flow regime and below atmospheric pressure has been investigated much less. Bidare et al. [12] and Guo et al. [14] found that in the continuum flow regime powder spattering is reduced in comparison to the molecular flow regime. Matthews et al. [8] and Bidare et al. [12] could show that track formation due to powder entraining is enabled. However, there is no study investigating LPBF tracks and the surrounding affected powder layer for process pressures above $20 \mathrm{mbar}$, although Bidare et al. [12] already concluded that the pressure regime between 50 mbar and 1 bar could provide an interesting window, but that further investigation is required, as no evaluations of the spattering and LPBF tracks are available for this process pressure range. In addition, only minor technical adjustments would be required for the system implementation in this pressure regime.

In this work, LPBF single tracks are generated in the process pressure range from 1 mbar to atmospheric pressure. Although, as mentioned above, the interesting range is from 50 mbar to 1 bar, the investigated range is expanded to $1 \mathrm{mbar}$ in order to determine the transition from the molecular to the continuum flow regime. The affected powder layer adjacent to the single tracks is 3D scanned, visualized, and evaluated. Surface profiles and cross sections for the materials CP titanium and Maraging steel are calculated. Powder spattering between 200 mbar and atmospheric pressure is quantified for the first time. The findings are discussed in the light of the previously presented literature to assess whether a process with reduced process pressure can provide benefits over a process at atmospheric pressure.

\section{Experimental details}

In the present work commercially pure $(\mathrm{CP})$ titanium grade 2 (TLS Technik SpezialpulverTM, Germany) with the sieve fraction $15-53 \mu \mathrm{m}$ and Maraging steel 1.2709 (LPW M300, LPW'M , UK) with the sieve fraction 15$45 \mu \mathrm{m}$ were used. Table 1 summarizes the particle sizes measured with a laser diffraction particle size analyzer (Malvern Mastersizer 3000, Malvern ${ }^{\mathrm{TM}}$, UK), and the tap/bulk density according to ASTM B527 for both powders. The chemical analyses are TLS specification values for titanium and actual values for steel measured by LPW. The scanning electron microscopy (SEM) images in Fig. $1 \mathrm{a}$ and $\mathrm{b}$ show the spherically shaped titanium and steel powder particles with small satellites.
The LPBF experiments were performed on an AconityLAB (Aconity ${ }^{\mathrm{TM}}$, Germany) machine equipped with a $1064 \mathrm{~nm}, 400 \mathrm{~W}$ fiber laser (YLR-400-AC, IPG $^{\mathrm{TM}}$, USA), a Raylase SUPERSCAN-IIE-20 2D laser scanner, and a F-Theta that sets a spot size of $50 \mu \mathrm{m}$ on the building area. A Hena 61 (Pfeiffer Vacuum $^{\mathrm{TM}}$, Germany) vacuum pump was used to evacuate the building chamber. Process pressures between 1 mbar and 950 mbar (atmospheric pressure) were controlled using an EVR 116 control gauge (Pfeiffer Vacuum ${ }^{\mathrm{TM}}$, Germany) to regulate the pumping rate (downstream pressure control) while constantly purging the system with argon. For the pressure measurement, the pressure gauge PCR 280 (Pfeiffer Vacuum ${ }^{\mathrm{TM}}$, Germany) was used.

With a coater blade, a powder layer of $60 \pm 5 \mu \mathrm{m}$ was applied to a $\varnothing 70 \mathrm{~mm}$ substrate plate made of the respective material. Tracks with a length of $10 \mathrm{~mm}$, referred to below as single tracks, were produced with different scanning parameters and different process pressures (see Table 2). The linear energy density, defined as the ratio of laser power to scanning speed, was kept constant in all experiments to ensure the comparability of the results in terms of energy input. According to [13], an adaption of the process parameter in low pressure conditions is necessary. Therefore, preliminary test was carried out and $0.16 \mathrm{~J} / \mathrm{mm}$ was found to be a suitable linear energy density for both titanium and Maraging steel processed with a $50 \mu \mathrm{m}$ laser spot. The single tracks were made at a distance of $5 \mathrm{~mm}$ from each other to avoid mutual influence. An Infinite FocusPortable G1 (Bruker Alicona ${ }^{\mathrm{TM}}$, USA) focus variation microscope was used to gather $3 \mathrm{D}$ scans of each track in two different states with a resolution of $2 \mu \mathrm{m}$. The first scan was made within the process chamber, with the loose powder layer still on the substrate plate. The second scan was made after removing the powder, thereby exposing solely the consolidated single tracks. For the further evaluations, the $3 \mathrm{D}$ data $1.5 \mathrm{~mm}$ after the start and $1.5 \mathrm{~mm}$ before the end of the respective track (longitudinal direction) and $\pm 1 \mathrm{~mm}$ from the track center (transverse direction) were used. A description of the process of data acquisition and evaluation can be seen in Fig. 2.

The 3D data were displayed as height maps (see Figs. 3 and 4) and were used to calculate transverse profiles. This was done by calculating the mean $z$-height along $y$ direction for every data point in $\mathrm{x}$. The resulting curves in Fig. 5 represent the mean surface profile of the powder bed and the single track. The mean cross-sectional area (see Fig. 6a) was evaluated by integrating over transverse single track profiles (without powder layer) at a sampling interval of $300 \mu \mathrm{m}$ (23 measurements for each parameter set) and by calculating mean values and standard 
Table 1 Powder properties

\begin{tabular}{|c|c|c|c|c|c|}
\hline Name & Description & Supplier & Particle size & Powder density & Chemical analysis \\
\hline Titanium & $\mathrm{CP}$ titanium grade 2 & TLS & $\begin{array}{l}\text { D10: } 21.9 \mu \mathrm{m} \\
\text { D50: } 35.2 \mu \mathrm{m} \\
\text { D90: } 54.7 \mu \mathrm{m}\end{array}$ & $\begin{array}{l}\text { Bulk: } 2.47 \pm 0.06 \mathrm{~g} / \mathrm{cm}^{3} \\
\text { Tap: } 2.82 \pm 0.04 \mathrm{~g} / \mathrm{cm}^{3}\end{array}$ & $\begin{array}{l}\text { C: }<0.08 \text { wt. } \% \\
\text { Fe: }<0.30 \text { wt. } \% \\
\text { O: }<0.25 \text { wt. } \% \\
\text { N: }<0.03 \text { wt. } \% \\
\text { H: }<0.0125 \text { wt. } \% \\
\text { Ti: Bal. }\end{array}$ \\
\hline Steel & Maraging steel 1.2709 & LPW & $\begin{array}{l}\text { D10: } 16.6 \mu \mathrm{m} \\
\text { D50: } 28.6 \mu \mathrm{m} \\
\text { D90: } 48.7 \mu \mathrm{m}\end{array}$ & $\begin{array}{l}\text { Bulk: } 4.35 \pm 0.10 \mathrm{~g} / \mathrm{cm}^{3} \\
\text { Tap: } 4.83 \pm 0.10 \mathrm{~g} / \mathrm{cm}^{3}\end{array}$ & $\begin{array}{l}\text { Ni: } 17.7 \text { wt. } \% \\
\text { Co: } 9.2 \text { wt. } \% \\
\text { Mo: } 4.7 \text { wt. } \% \\
\text { Ti: } 1.1 \text { wt. } \% \\
\text { Cr: } 0.13 \text { wt. } \% \\
\text { Si: } 0.02 \text { wt. } \% \\
\text { Mn: } 0.02 \text { wt. } \% \\
\text { O: } 0.02 \text { wt. } \% \\
\text { C, P, S, N: < } 0.01 \text { wt. } \% \\
\text { Fe: Bal. }\end{array}$ \\
\hline
\end{tabular}

deviations. The mean cross-sectional area of a single track is a measure for how much powder was consolidated under certain conditions. It does not consider molten/ solidified substrate material. The change of spattering relative to atmospheric pressure (Fig. 6b) was calculated for process pressures $\geq 200 \mathrm{mbar}$ and for the laser parameters $113 \mathrm{~W} / 700 \mathrm{~mm} / \mathrm{s}$, which are closest to typical atmospheric pressure parameters. Calculation was done according to

rel.spatter $(p)=\left(\frac{P(p)-C O R}{P_{\text {atmospheric }}}-1\right) \cdot 100$

$C O R=\frac{S(p)-S_{\text {atmospheric }}}{P D}$

where $p$ is the process pressure, $P D$ the powder layer density, $S$ the cross-sectional area of the single track, and $P$ the disturbed powder bed area (see Fig. 2).

Formula (1) calculates the relative amount of spatters at a given process pressure compared with ambient pressure by comparing the areas $\mathrm{S}$ and $\mathrm{P}$. The area $\mathrm{P}$ is a measure for the powder that is missing compared with the initial, undisturbed powder layer. The missing powder was either transported more than $\pm 1 \mathrm{~mm}$ from the center of the track or contributed to the single track. Therefore, comparing the difference of the areas $\mathrm{P}$ at a given process pressure to atmospheric pressure shows the relative change in spattering for a constant single track cross-sectional area. Since the single track crosssectional areas, and therefore the amount of powder that contributed to the single track, are slightly different for different process pressure (see Fig. 6a), the correction term COR is introduced in formula (1). A single track is assumed to be fully dense; therefore, the difference in the single track crosssectional area needs to be divided by PD, the density of the powder layer. For PD the relative bulk densities of the Ti and steel powder were used. According to the results in [17] the bulk density marks a lower limit for the powder layer density of typical LPBF powders at a layer thickness of $60 \mu \mathrm{m}$. Therefore, the calculations presented here represent the upper
Fig. 1 SEM images of a CP titanium grade 2 and $\mathbf{b}$ Maraging steel 1.2709 powder
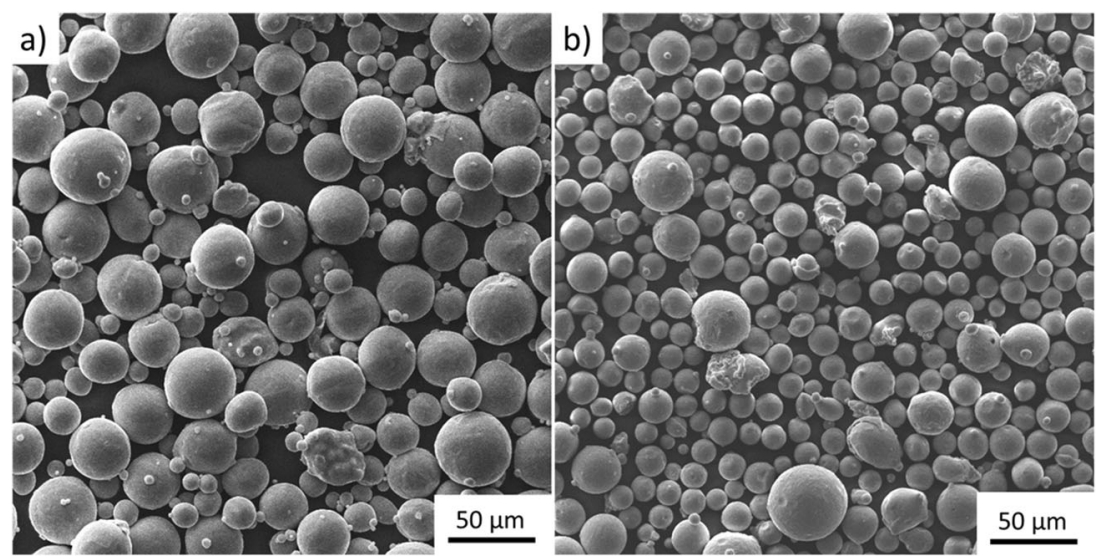
Table 2 Scanning parameters and process pressures for single tracks. For every set of parameters, one single track was produced

\begin{tabular}{llllll}
\hline Material & Name & Laser power $(\mathrm{W})$ & $\begin{array}{l}\text { Scanning speed } \\
(\mathrm{mm} / \mathrm{s})\end{array}$ & $\begin{array}{l}\text { Linear energy density } \\
(\mathrm{J} / \mathrm{mm})\end{array}$ & $\begin{array}{l}\text { Process pressure } \\
(\mathrm{mbar})\end{array}$ \\
\hline CP titanium Grade 2 & $\mathrm{T} 1$ & 113 & 700 & 0.16 & $1,3,5,10,50,100,200,500,750,950$ \\
& $\mathrm{~T} 2$ & 225 & 1400 & 0.16 \\
Maraging steel 1.2709 & $\mathrm{S} 1$ & 113 & 700 & \\
& $\mathrm{~S} 2$ & 225 & 1400 & \\
\hline
\end{tabular}

limit for the amount of spattering. The relative bulk densities of $0.55 \pm 0.1$ for $\mathrm{Ti}$ and $0.54 \pm 0.01$ for steel were calculated using the theoretical densities of $4.5 \mathrm{~g} / \mathrm{cm}^{3}$ for $\mathrm{Ti}$ and $8.0 \mathrm{~g} / \mathrm{cm}^{3}$ for the Maraging steel 1.2709 and the bulk densities in Table 2. The error of the relative amount of spatters was calculated by considering the effects of error propagation.

\section{Results and discussion}

The height maps of titanium (T1 and T2) and steel (S1 and S2) single tracks produced with various laser parameters and process pressures are presented in Fig. 3. The surface profiles in transverse direction of the same single tracks are found in Fig. 5a-d as red lines. Both figures reveal that for process pressures $\leq 10$ mbar, only a small amount (T1, T2, and S2) or no (S1) powder contributes to the formation of the single track. Almost only substrate plate material is remelted. The cross-sectional area of the single tracks in Fig. 6a confirms this finding as well. Furthermore, track S2 was accompanied by an adjacent depression on the substrate. This phenomenon is well known in laser welding and is referred to as undercutting [18]. It occurs at high welding speeds when wetting of the sides of the weld seam is prevented because the backflow of liquid metal is too high due to Marangoni convection [18-20]. Besides the lack of significant incorporation of powder into the single track for process pressures $\leq 10$ mbar, the height maps in Fig. 4 and the corresponding surface profiles, gray lines in Fig. $5 \mathrm{a}-\mathrm{d}$, reveal that exposing a loose powder layer to high power laser radiation leads to a significant powder denudation adjacent to the single track. Between 1 mbar and 10 mbar, the width of the denuded zone decreases with increasing pressure, while the shape of the powder layer surface remains similar: A zone entirely free of loose powder adjacent to the single track accompanied by a pile up. Since the area of the denuded zone in Fig. 5 is larger than that of the pile up, it can be concluded that a significant amount of powder was ejected further outward. The data in Fig. 5 show that the described behavior is found for both titanium and Maraging steel, but the laser parameter alters the strength of its appearance. Higher laser speed and power lead to a wider area where the powder layer was visibly influenced.

The reason for the occurrence of the denudation zone and the missing contribution of the powder to the formation of the single track lies in the high mean free path of the argon atoms of the process atmosphere for pressures $\leq 10$ mbar. Free molecular flow is predominant. The metal vapor expands freely, entrains powder particles, and moves them away from the melt pool [8, 12]. This powder repelling mechanism prevents powder from being incorporated into the melt pool.

With increasing pressure, the mean free path of the atoms in the process atmosphere is reduced and the gas flow regime is changed from molecular flow towards a continuum flow [8]. The amount of consolidated powder rises, because the metal vapor flux does not expand freely as at lower pressure but interacts with the process atmosphere [8, 14]. The vapor flux expands jet-like in direction of the laser beam and induces
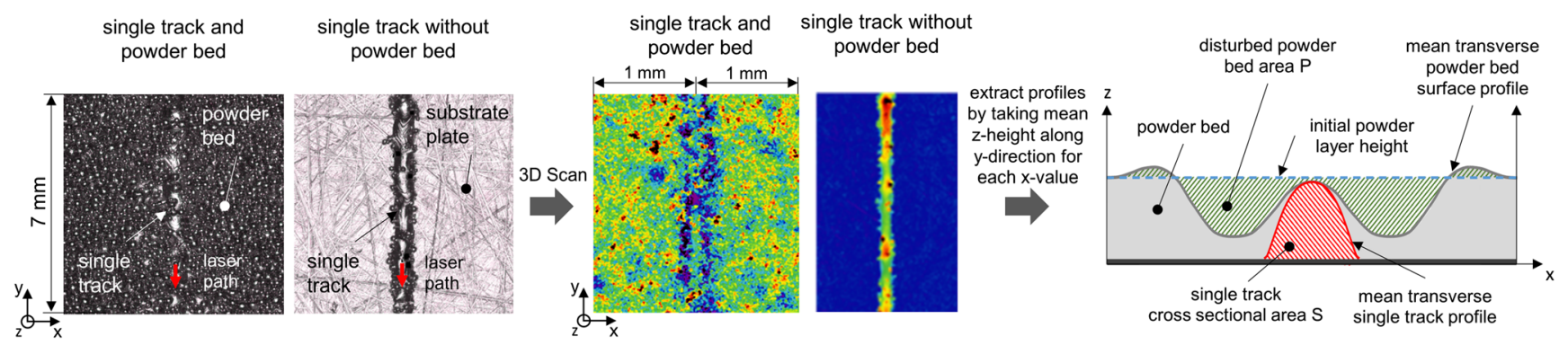

Fig. 2 Procedure for data acquisition and evaluation 


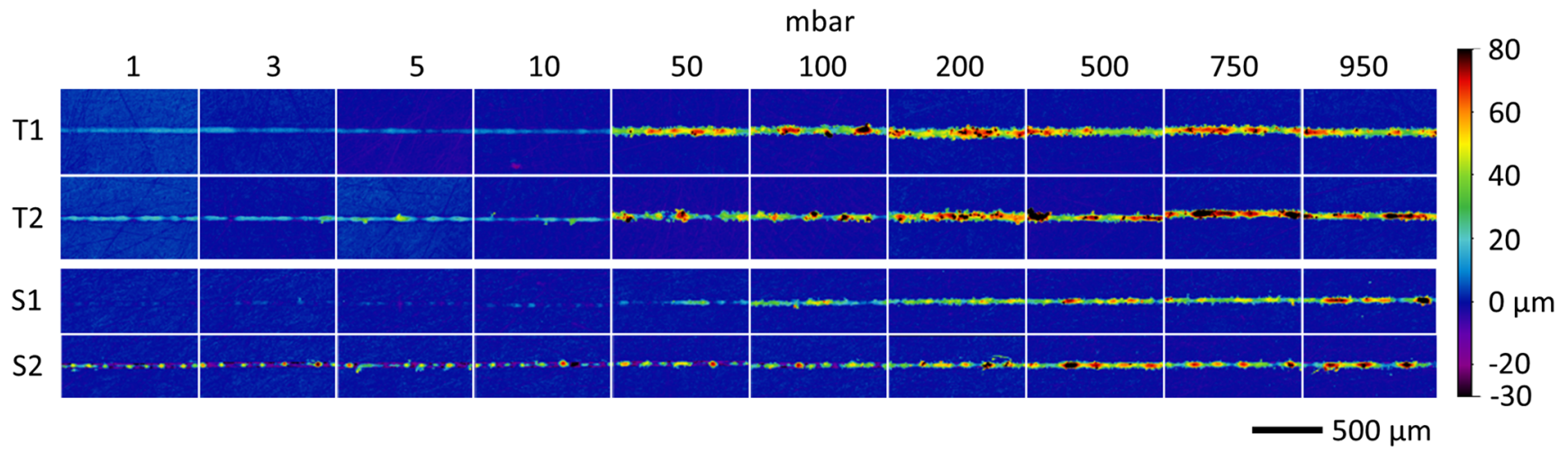

Fig. 3 Height maps after removing the powder of single tracks made of CP titanium grade 2 and Maraging steel 1.2709 produced with various laser parameters and process pressures. T1 (titanium)-113 W,

$700 \mathrm{~mm} / \mathrm{s} ;$ T2 (titanium) - $225 \mathrm{~W}, 1400 \mathrm{~mm} / \mathrm{s}$; S1 (steel)—113 W, $700 \mathrm{~mm} / \mathrm{s} ; \mathrm{S} 2$ (steel) $-225 \mathrm{~W}, 1400 \mathrm{~mm} / \mathrm{s}$

a gas flow towards the melt pool, which has an about 10 times lower velocity than the metal vapor jet itself [21]. It is capable of efficiently entraining powder particles $[8,12,14]$ and moving them towards the melt pool. A zone entirely free of powder particles adjacent to the single track and the corresponding pile up are no longer found. Rather, an area emerges in which shares of the powder layer are missing at a certain distance from the single track. This explains that at process pressures $>10$ mbar, the height (Fig. 3) and the cross-sectional area (Fig. 6a) as well as the red line in Fig. 5) of the single track increase. This statement applies to both titanium and Maraging steel, processed with both $113 \mathrm{~W} / 700 \mathrm{~mm} / \mathrm{s}$ and $225 \mathrm{~W} / 1400 \mathrm{~mm} / \mathrm{s}$. Figures 4 and 5 also reveal that the amount of powder incorporated into the melt pool depends on the material used. With identical scanning conditions, this amount is significantly larger for titanium than for steel. Figure 5 reveals that with Maraging steel the single track is entirely covered with powder. This means that under the process parameters used, the steel powder is transported in the direction of the single track by the mechanism discussed above but is not completely melted. It can be concluded that the temperature of the single track was already below the solidus temperature before this transportation process was completed.

For all experiments, the cross-sectional area of the single tracks at process pressures between 200 mbar and atmospheric pressure varies by a maximum of $31 \%$ (28\% for T1, $17 \%$ for $\mathrm{T} 2,26 \%$ for $\mathrm{S} 1$, and $31 \%$ for S2). For titanium and the Maraging steel, as shown for $\mathrm{T} 1$ and $\mathrm{S} 1$ in Fig. 6b, the

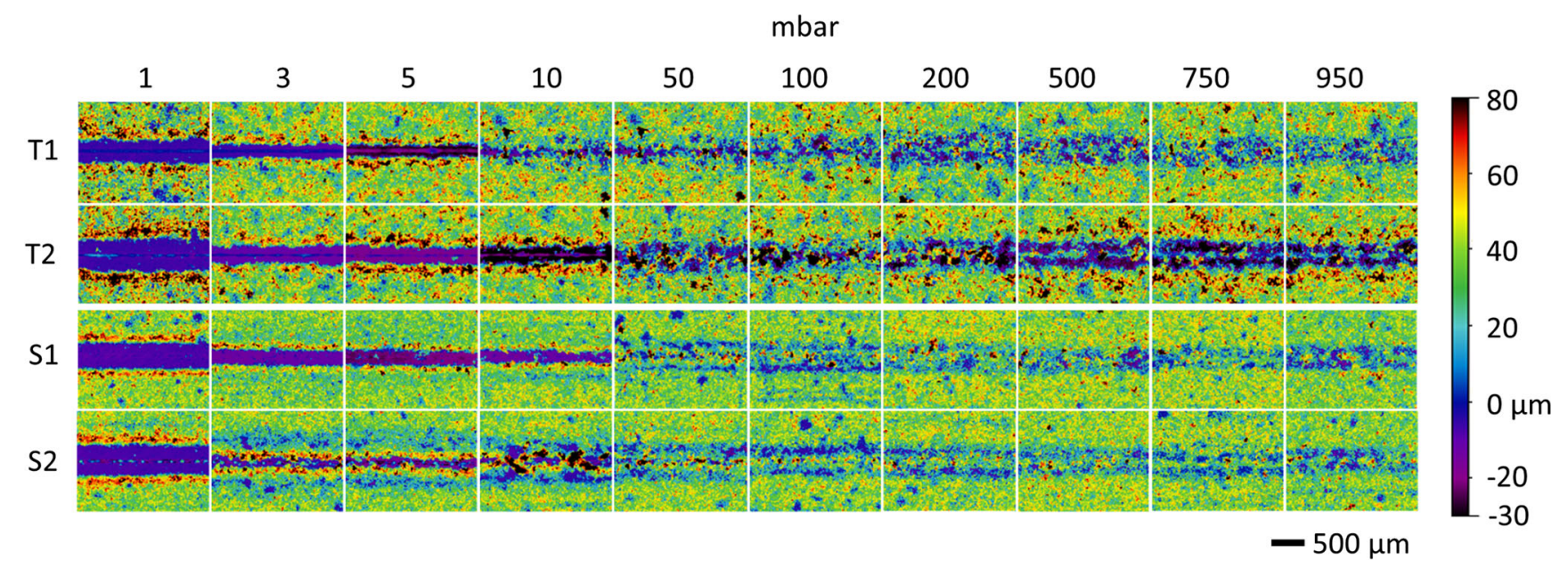

Fig. 4 Height maps of single tracks with surrounding powder layer made of CP titanium grade 2 and Maraging steel 1.2709 produced with various laser parameters and process pressures. T1 (titanium)-
$113 \mathrm{~W}, 700 \mathrm{~mm} / \mathrm{s}$; T2 (titanium)—225 W, $1400 \mathrm{~mm} / \mathrm{s}$; S1 (steel)— $113 \mathrm{~W}, 700 \mathrm{~mm} / \mathrm{s}$; S2 (steel)-225 W, $1400 \mathrm{~mm} / \mathrm{s}$ 
a)

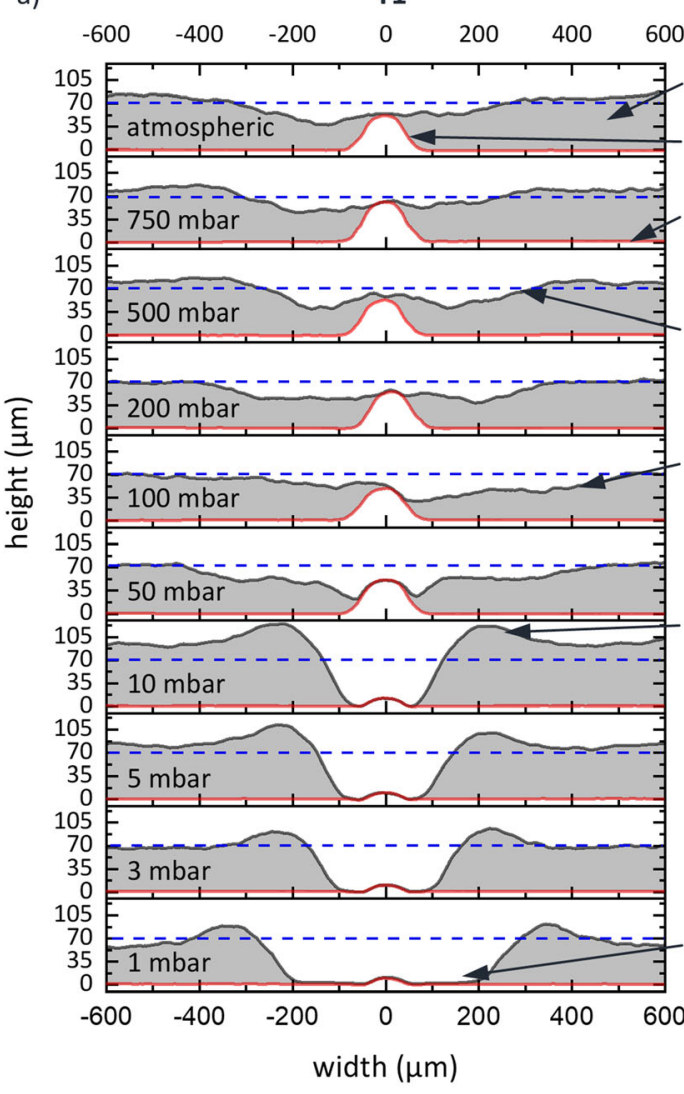

c)

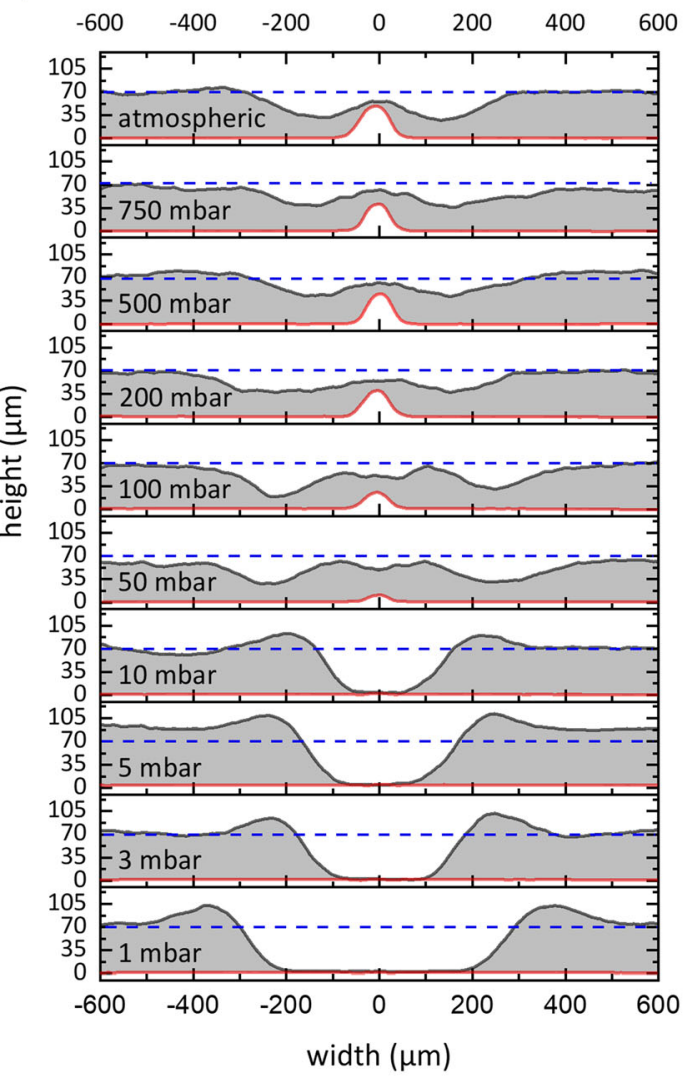

b)

T2

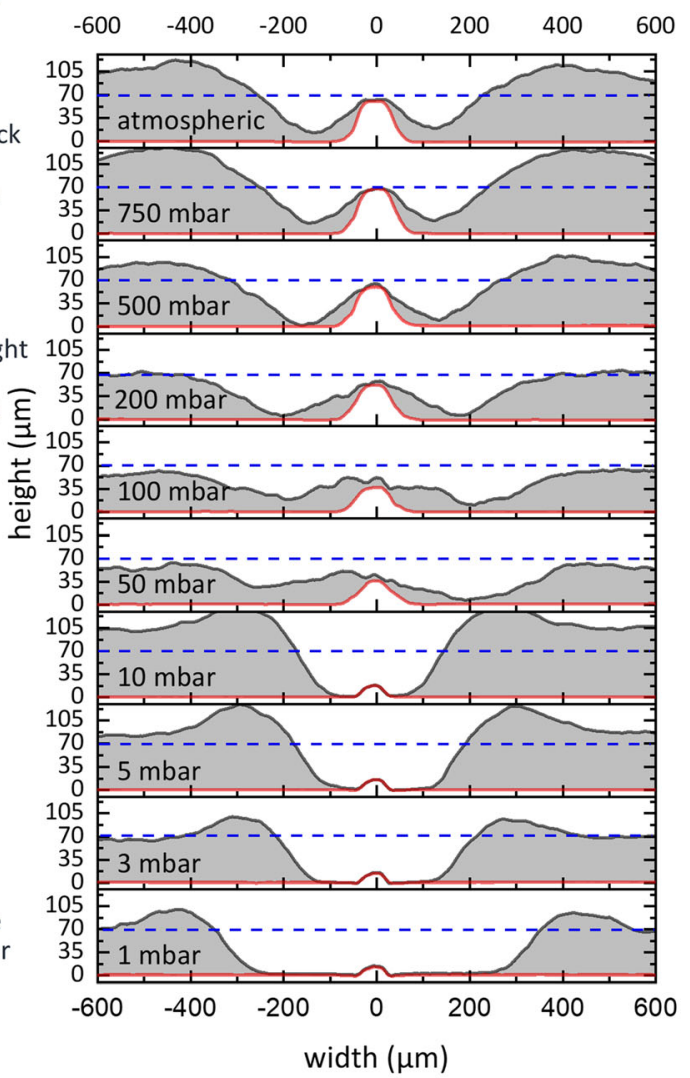

d)

$\begin{array}{rrrrrrr}-600 & -400 & -200 & 0 & 200 & 400 & 600\end{array}$

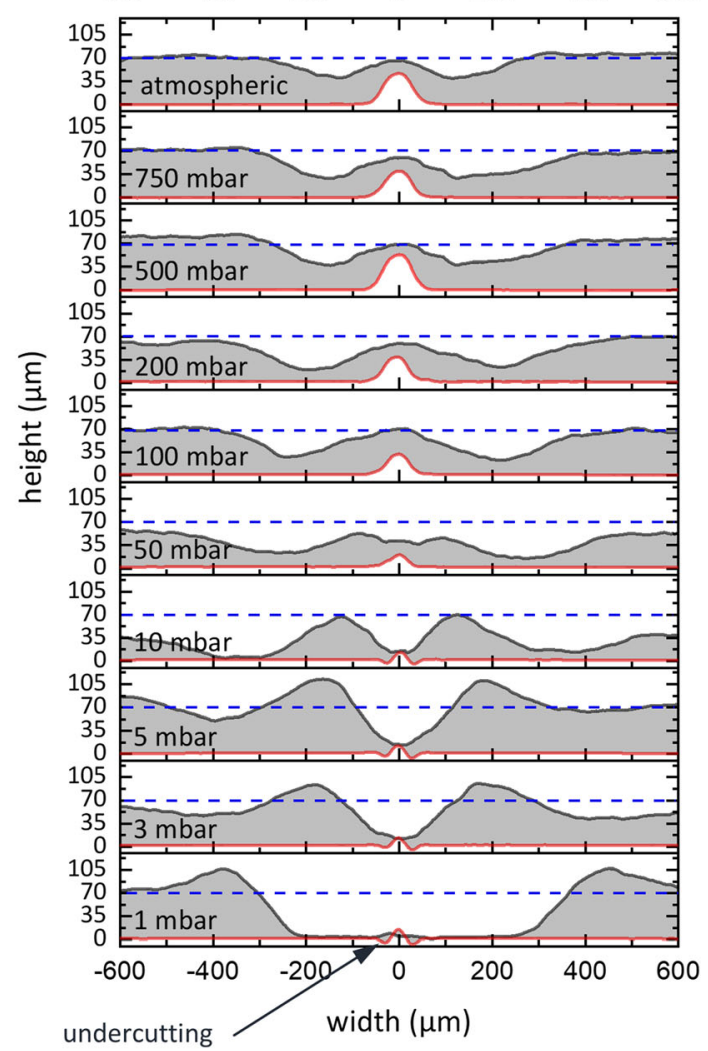


Fig. 5 Mean transverse profiles of the substrate plate, the single track surface (red line), and the surface of the powder layer (gray line) produced with various laser parameters and process pressures. The gray area represents the cross-sectional area of the powder layer. a T1 (titanium) $-113 \mathrm{~W}, 700 \mathrm{~mm} / \mathrm{s} ; \mathbf{b}$ T2 (titanium) $-225 \mathrm{~W}, 1400 \mathrm{~mm} / \mathrm{s} ; \mathbf{c}$ S1 (steel)-113 W, $700 \mathrm{~mm} / \mathrm{s}$; d S2 (steel)-225 W, $1400 \mathrm{~mm} / \mathrm{s}$

spattering in the pressure range from 200 mbar to atmospheric pressure does not change significantly within the uncertainty of the method used. Spattering increases by $12 \%$ at 200 mbar for $\mathrm{S} 1$ and less than $\pm 5 \%$ for all other parameter sets related to the value determined at atmospheric pressure. This lies within typical process variations.

In the LPBF process at reduced process pressure below $\sim 50$ mbar, previous studies have shown that the amount of disruption in the powder layer [12] and the amount of spatters [14] increase significantly compared with the process at atmospheric pressure. Here, for the first time, LPBF in process pressure $>50$ mbar was investigated and the pressure range 200 mbar $\leq \mathrm{p}<1$ bar has been identified in which the quantity of spatters is similar to the process at atmospheric pressure, while the individual tracks show only slight changes in the cross-sectional area. This opens the possibility for an improved process due to enhanced laser penetration depth at 200 mbar $\leq$ p $<1$ bar, but needs further investigation.

\section{Conclusion and outlook}

Increasing the process stability is one of the greatest challenges in order to fully exploit the potential of LPBF. One suggested approach is to perform the LPBF process under vacuum. In laser welding, a process closely related to LPBF, spattering was found to be significantly reduced when conducted in vacuum [4]. For the question of whether the benefits

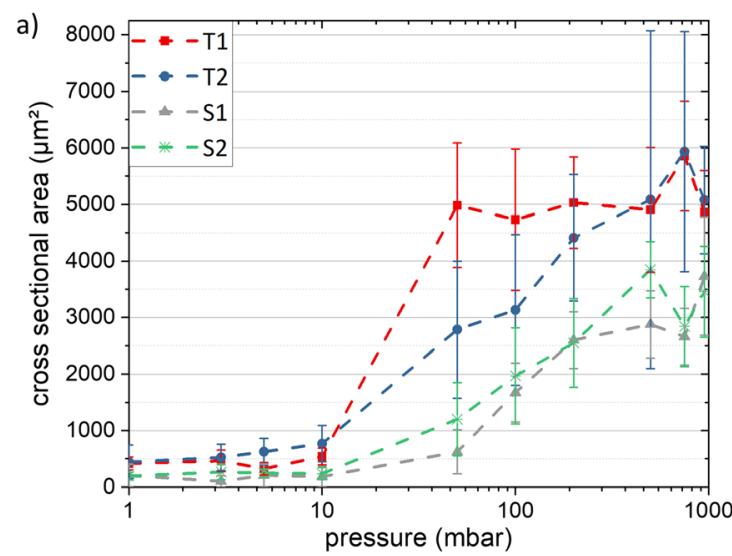

Fig. 6 a Mean cross-sectional area of single tracks produced with various laser parameters and process pressures evaluated by integrating over transverse single track profiles (without powder layer) at a sampling interval of $300 \mu \mathrm{m}$. b Relative change of spattering compared with of vacuum laser welding can be transferred to vacuum LPBF, the results of this work together with a thorough evaluation of the available literature allow the following conclusions to be drawn:

- The incorporation of powder particles into the melt pool via a gas flow induced by directional evaporation begins to be effective in the continuum flow regime at process pressures $>10$ mbar. This incorporation changes significantly $<200$ mbar and less at pressures $\geq 200$ mbar. For both CP titanium grade 2 and the Maraging steel 1.2709 under the scanning parameters employed the crosssectional area of the single tracks above this pressure change less than $31 \%$.

- The amount of powder incorporated into the melt pool is different for CP titanium grade 2 and Maraging steel 1.2709. With identical scanning conditions, this amount of powder is significantly larger for titanium than for steel.

- The amount of spattering at process pressures above 200 mbar does not change significantly for CP titanium grade 2 and for the Maraging steel 1.2709 for $113 \mathrm{~W} / 700 \mathrm{~mm} / \mathrm{s}$.

- Since the interaction between the laser beam and the plasma plume decreases with decreasing pressure, a potentially advantageous process window opens at pressures from $\geq 200$ mbar to atmospheric pressure. For laser welding, it was found that with less interaction the penetration depth of the laser beam doubles when the pressure is reduced from atmospheric pressure to 30 mbar [4]. A significant increase in penetration depth was also found for LPBF when lowering the pressure to 50 mbar [12]. An increase in the laser penetration depth can also be expected for LPBF, when the pressure is reduced to 200 mbar. This needs to be investigated in further studies.

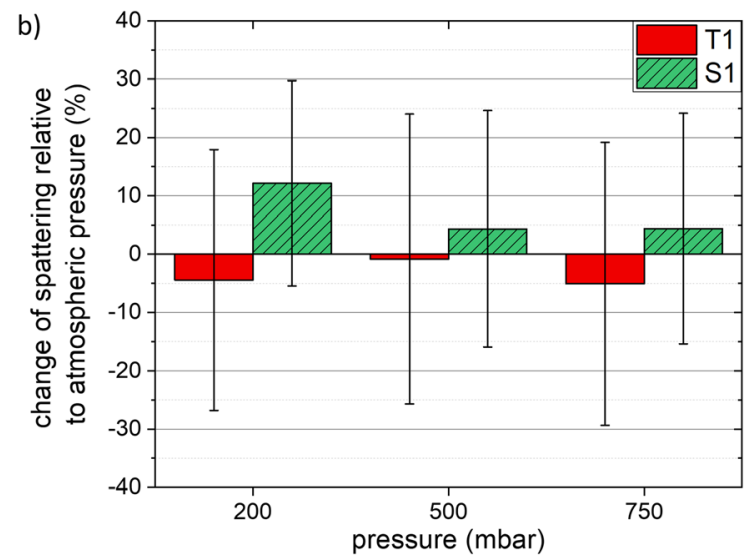

atmospheric pressure for process pressures $\geq 200 \mathrm{mbar}$. T1 (titanium) $113 \mathrm{~W}, 700 \mathrm{~mm} / \mathrm{s}$; T2 (titanium) - $225 \mathrm{~W}, 1400 \mathrm{~mm} / \mathrm{s} ; \mathrm{S} 1$ (steel)—113 W, $700 \mathrm{~mm} / \mathrm{s} ; \mathrm{S} 2$ (steel) $-225 \mathrm{~W}, 1400 \mathrm{~mm} / \mathrm{s}$ 
Acknowledgments The authors would like to take this opportunity to thank the Alicona Imaging $\mathrm{GmbH}$ for loaning the Infinite FocusPortable G1 measuring device.

Funding Open access funding provided by University of Innsbruck and Medical University of Innsbruck.

Open Access This article is licensed under a Creative Commons Attribution 4.0 International License, which permits use, sharing, adaptation, distribution and reproduction in any medium or format, as long as you give appropriate credit to the original author(s) and the source, provide a link to the Creative Commons licence, and indicate if changes were made. The images or other third party material in this article are included in the article's Creative Commons licence, unless indicated otherwise in a credit line to the material. If material is not included in the article's Creative Commons licence and your intended use is not permitted by statutory regulation or exceeds the permitted use, you will need to obtain permission directly from the copyright holder. To view a copy of this licence, visit http://creativecommons.org/licenses/by/4.0/.

\section{References}

1. Herzog D, Seyda V, Wycisk E, Emmelmann C (2016) Additive manufacturing of metals. Acta Mater 117:371-392. https://doi. org/10.1016/J.ACTAMAT.2016.07.019

2. Gibson I, Rosen DW, Stucker B (2010) Additive manufacturing technologies: rapid prototyping to direct digital manufacturing. https://doi.org/10.1007/978-1-4419-1120-9.

3. Petrick IJ, Simpson TW (2013) 3D printing disrupts manufacturing. Res Technol Manag 56:12-16. https://doi.org/10.5437/ $08956308 X 5606193$

4. Luo Y, Tang X, Lu F, Chen Q, Cui H (2015) Effect of subatmospheric pressure on plasma plume in fiber laser welding. J Mater Process Technol 215:219-224. https://doi.org/10.1016/j. jmatprotec.2014.08.011

5. Sato Y, Tsukamoto M, Yamashita Y, Masuno S, Abe N (2016) Experimental study on Ti alloy plate fabrication by vacuum selective laser melting. In: Laser 3D Manuf. III, p 97381C. https://doi. org/10.1117/12.2212654

6. Sato Y, Tsukamoto M, Yamashita Y (2015) Surface morphology of Ti-6Al-4V plate fabricated by vacuum selective laser melting. Appl Phys B Lasers Opt 119:545-549. https://doi.org/10.1007/ s00340-015-6059-3

7. Sato Y, Tsukamoto M, Masuno S, Yamashita Y, Yamashita K, Tanigawa D, Abe N (2016) Investigation of the microstructure and surface morphology of a Ti6Al4V plate fabricated by vacuum selective laser melting. Appl Phys A Mater Sci Process 122. https:// doi.org/10.1007/s00339-016-9996-8

8. Matthews MJ, Guss G, Khairallah SA, Rubenchik AM, Depond PJ, King WE (2017) Denudation of metal powder layers in laser powder-bed fusion processes. Addit Manuf Handb Prod Dev Def Ind 114:677-693. https://doi.org/10.1201/9781315119106
9. Ly S, Rubenchik AM, Khairallah SA, Guss G, Matthews MJ (2017) Metal vapor micro-jet controls material redistribution in laser powder bed fusion additive manufacturing. Sci Rep 7. https://doi.org/10.1038/s41598-017-04237-z

10. Zhang B, Liao H, Coddet C (2013) Selective laser melting commercially pure Ti under vacuum. Vacuum. 95:25-29. https://doi. org/10.1016/j.vacuum.2013.02.003

11. Zhang B, Liao H, Coddet C (2013) Microstructure evolution and density behavior of CP Ti parts elaborated by Self-developed vacuum selective laser melting system. Appl Surf Sci 279:310-316. https://doi.org/10.1016/j.apsusc.2013.04.090

12. Bidare P, Bitharas I, Ward RM, Attallah MM, Moore AJ (2018) Laser powder bed fusion at sub-atmospheric pressures. Int J Mach Tools Manuf 130-131:65-72. https://doi.org/10.1016/j. ijmachtools.2018.03.007

13. Masmoudi A, Bolot R, Coddet C (2015) Investigation of the laserpowder-atmosphere interaction zone during the selective laser melting process. J Mater Process Technol 225:122-132. https://doi.org/ 10.1016/j.jmatprotec.2015.05.008

14. Guo Q, Zhao C, Escano LI, Young Z, Xiong L, Fezzaa K, Everhart W, Brown B, Sun T, Chen L (2018) Transient dynamics of powder spattering in laser powder bed fusion additive manufacturing process revealed by in-situ high-speed high-energy x-ray imaging. Acta Mater 151:169-180. https://doi.org/10.1016/j.actamat.2018. 03.036

15. Yin J, Yang L, Yang X, Zhu H, Wang D, Ke L, Wang Z, Wang G, Zeng $X$ (2019) High-power laser-matter interaction during laser powder bed fusion. Addit Manuf 29:100778. https://doi.org/10. 1016/j.addma.2019.100778

16. Bidare P, Bitharas I, Ward RM, Attallah MM, Moore AJ (2018) Laser powder bed fusion in high-pressure atmospheres. Int $\mathrm{J}$ Adv Manuf Technol 99:543-555. https://doi.org/10.1007/s00170-0182495-7

17. Brika SE, Letenneur M, Dion CA, Brailovski V (2020) Influence of particle morphology and size distribution on the powder flowability and laser powder bed fusion manufacturability of Ti-6Al-4V alloy. Addit Manuf 31:100929. https://doi.org/10.1016/j.addma.2019. 100929

18. Mills KC, Keene BJ, Brooks RF, Shirali A (1998) Marangoni effects in welding. Philos Trans R Soc A Math Phys Eng Sci 356: 911-925. https://doi.org/10.1098/rsta.1998.0196

19. Mendez PF, Eagar TW (2003) Penetration and defect formation in high-current arc welding. Weld J (Miami, Fla) 82. https://doi.org/ $10.2172 / 835707$

20. Zong R, Chen J, Wu CS, Padhy GK (2017) Influence of molten metal flow on undercutting formation in GMAW. Sci Technol Weld Join 22:198-207. https://doi.org/10.1080/13621718.2016. 1214406

21. Landau LD, Lifshitz EM (1966) Fluid Mechanics - Vol. 6. doi: https://doi.org/10.1063/1.3057567.

Publisher's note Springer Nature remains neutral with regard to jurisdictional claims in published maps and institutional affiliations. 